\title{
COMPARATIVE ANALYSIS OF THE TENSILE STRENGTH AND BREAKING EXTENSION OF THE SHEEP, GOAT AND SHEEP/GOAT FELT FABRICS
}

\author{
${ }^{1}$ E.S. Nwadiokwu, ${ }^{2}$ O.K. Sunmonu, ${ }^{3}$ A.S. Lawal, ${ }^{4}$ B.M Dauda \\ ${ }^{1}$ Chemical Fibre and Environmental Technology, Federal Institute of Industrial \\ Research, Oshodi (FIIRO)
}

${ }^{2,3,4}$ Department of Polymer and Textile Engineering, Ahmadu Bello University, Zaria.

esnwadiokwu@gmail.com

\begin{abstract}
The comparative analysis of the tensile strength and breaking extension of the sheep, goat and sheep/goat blend has been done. This research shows that the sheep felt fabrics has higher tensile strength followed by the sheep/goat felt fabric and lastly by the goat felt fabrics. While the goat felt fabrics has higher breaking extension followed by the sheep/goat felt fabrics and lastly by the sheep felt. This can be attributable to the nature of their felt fabrics which depends on their fibre characteristics. The sheep felt fabric is regarded as a strong fabric and less extensible because of the ease in which the protruding fibre scales interlocks and therefore can withstand more stress. The goat felt fabric has higher breaking extension properties because of the elastic nature of their fibres and as such can be regarded as a tough fabric.
\end{abstract}

Key words: Sheep felt fabrics, goat felt fabrics, sheep/goat felt fabrics, breaking extension, tensile strength. 


\subsection{INTRODUCTION}

Breaking strength and elongation are two prime quality attributes of any textile fabric. The strength and elongation of a fabric are important determinant as to the quality of such fabric. This strength and elongation properties are determined by various fibre properties, and interlocking ability of the felt fabrics

According to (Realff,et al., 1997), tensile strength is defined as a maximum load that a yarn or fabric specimen will endure when subjected to uni-axial tensile loading. (Taylor, 1959) also stated that tensile strength and elongation are the most important property of textile materials that differentiates a non-woven fabric from a woven and a knitted fabric. Thus in order to ensure the quality of a fabric, yarn as well as fibres, a demand for minimum fabric strength and elongation is added to the usual structural particulars of a fabric.

(Nikolic, et al., 2000; Majumdar, et al., 2008) reported that tensile strength of a fabric is a function of the fibresstrengthwhich gives a comprehensive check on quality of fibre, yarn, fabric as well as their processing.

Similarly, (Gabrijelcic,et al., 2008; Chattopadhyay, 2008), reported that breaking extension of a fabric is in close relation to the elasticity of the fibres or yarn used.

In this research, the sheep, goat and sheep/goat felt fabrics were subjected to both tensile strength and percentage elongation tests and their differences compared.

\subsection{MATERIALS AND METHODS}

\subsection{Materials}

Sheep felt fibrics.

Goat felt fabrics

Sheep/Goat felt fabrics

Fabric Tensile testing machine YG026D

\subsection{Methods}

The sheep, goat and sheep/goat felt fabrics were subjected to tensile testing specifically the tensile strength and percentage elongation using the fabric tensile testing machine.

The rate of extension was $100 \%$ per minute and a maximum load of $100 \mathrm{~kg}$ was used for the test. Cross head speed was $50 \mathrm{~mm}$ per minute and chart speed was $100 \mathrm{~mm}$ per minute.

Tensile strength which is simply defined as stress at break was calculated as force/unit area. $\frac{\text { Force }}{\text { Area }}$

The percentage elongation is calculated as Percentage elongation $=\frac{\text { elongation }}{\text { initial length }} \mathbf{x 1 0 0}(\%)$ 


\subsection{RESULTS AND DISCUSSION}

\subsection{Tensile Strength of the Felt Fabrics}

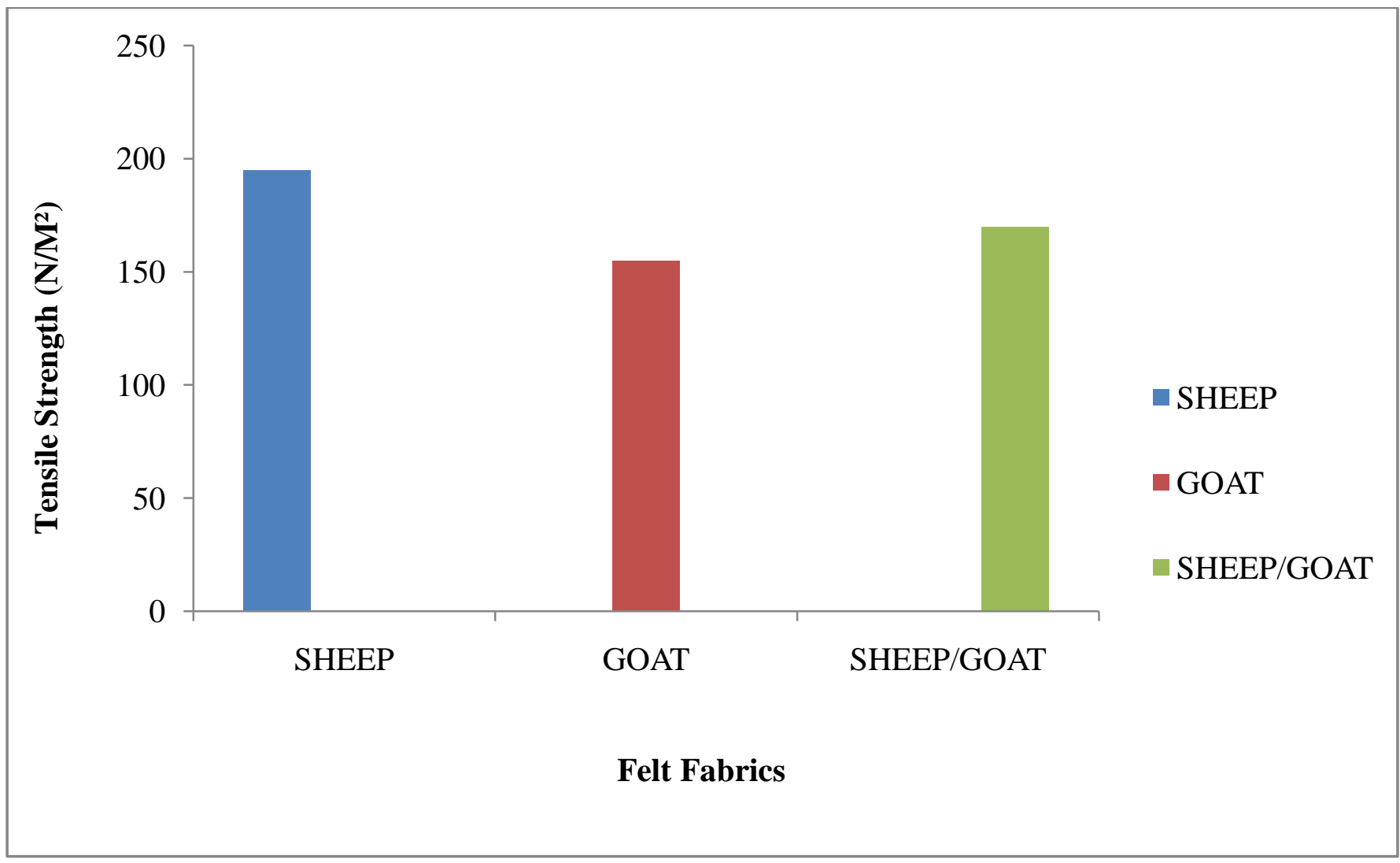

Figure 1: Bar Chart Showing the Tensile Strength of the Sheep, Goat and Sheep/Goat Felt Fabrics.

Figure 1 show that the sheep felt fabric has higher tensile strength than the sheep/goat felt and the goat felt fabrics. This is because of its overlapping and rough scales (Christoe, et al, 1998). This results to a more interlocked felt fabric making it to be strong and enable to withstand more stress when a force or load is applied under tension. Therefore, the sheep felt fabrics are regarded as strong fabrics.

The goat fibre on the other hand, has a flat, fewer and relatively smoother scales (De Boss, 2006). Therefore has a lesser interlocking of the fibres and may not withstand high stress. The sheep /goat blend felt fabrics also have high tensile strength although not up to the sheep felt fabrics but more than the goat felt fabrics. This can also be attributable to the bonding that exists between the sheep and goat fibres by the interlocking of the overlapping and the smooth scales. 


\subsection{Percentage Elongation $(\%)$ of the Felt Fabrics}

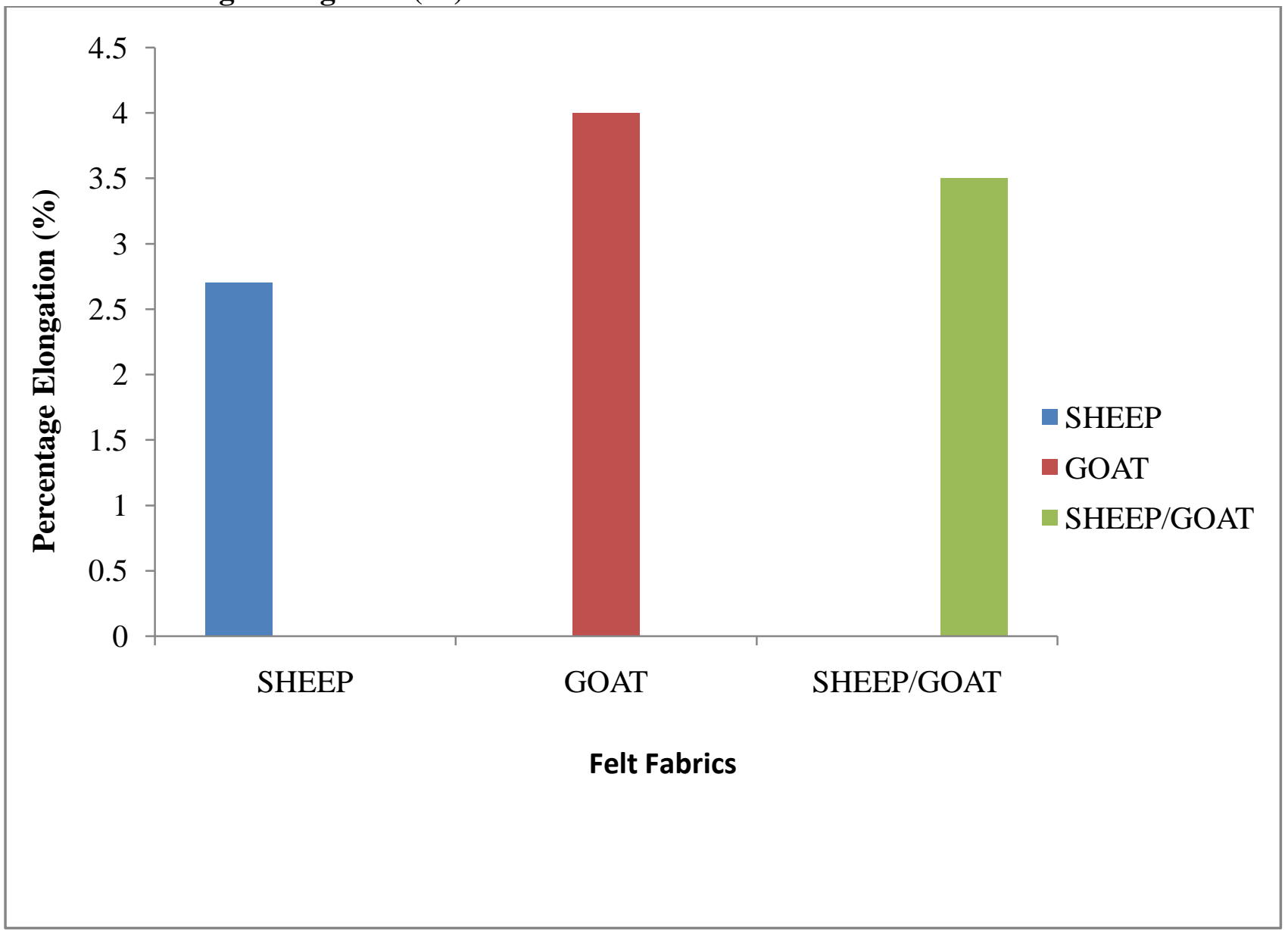

Figure 2: Bar Chart Showingthe Percentage Elongation (\%) of the Sheep, Goat and Sheep/Goat Felt Fabrics

Fig 2 shows the percentage elongation of the Nigerian felt fabrics. It was observed that the goat felt fabric has higher elongation compared to the sheep/goat blend and the sheep felt fabrics. This may be attributable to the elastic nature of the fibre scales. Therefore, the goat felt fabric is regarded as a tough fabric. However, the sheep/goat blend felt fabrics has a higher percentage elongation than the sheep felt fabrics probably due to the presence of the goat fibres scale properties in its blend.

\section{CONCLUSION}

This research work gives insight on the tensile strength and elongation properties of the sheep, goat and sheep/goat felt fabrics. The sheep can withstand more stress than the goat and sheep/goat blend when a force is applied to it and it is said to be a strong fabric and therefore has higher tensile strength. The sheep/goat blend can also withstand stress because of the presence of sheep fibres in the blend unlike the goat felt fabrics.

On the other hand, the goat felt fabrics has higher elastic properties and is regarded as a tough fabric and can withstand impact more than the sheep. This is followed by the sheep/goat because of the presence of the goat in the blend.

This research, therefore gives a clue on the application of these felt fabrics where high tensile strength and elongation is needed both at home and the industries. 


\section{REFERENCES}

Chattopadhyay, R; (2008), "Design of Apparel Fabrics: Role of Fiber, Yarn and Fabric

Parameters on its Functional Attributes" Journal of Textile Engineering, V. 54, 2008, PP. 179-190.

Gabrijelcic, H; Cernosa, E and Dimitrovski, K. (2008), "Influence of Weave and Weft

Characteristics onTensile Properties of Fabrics", Fibers and Textiles in Eastern Europe, V. 16, Apr - June, 2008. PP. 45-51.

Majumdar, A., Ghosh, A.,Saha, S. S., Roy, A., Barman, S., Panigrahi, D., and Biswas, A.

(2008),"Empirical Modelingof Tensile Strength of Woven Fabrics” Fibers and Polymers, V. 19, 2008, pp. 240-245

Nikolic, M., Michailovic, T., and Simovic, Lj. (2000), "Real Value of Weave Binding Coefficient as a Factor of Woven Fabric Strength", Fibers and Textiles in Eastern Europe, V.8, Oct-Dec 2000, pp. 74-78.

Realff, M. L.; Boyce, M. C.; and Backer S. (1997), “A Micro-Mechanical Model of the Tensile Behavior of Woven Fabric" Textile Res. J., V.67, N0.6, June1997, pp.445459.

Taylor, H.M. (1959), “Tensile and Tearing Strength of Cotton Cloth” J. Textile Inst., V.50, 1959, pp.T161-T188. 